\title{
Desnitrificação em um sistema simplificado de tratamento de esgoto
}

\section{Denitrification in a simple wastewater treatment system}

\begin{abstract}
Adriano Luiz Tonetti
Doutor em Engenharia Civil (Área de Saneamento e Ambiente) pela Universidade Estadual de Campinas (Unicamp). Professor doutor da Unicamp Campinas (SP), Brasil.

Bruno Coraucci Filho

Doutor em Engenharia Civil pela Universidade de São Paulo (USP) - São Paulo (SP), Brasil. Professor titular da Unicamp - Campinas (SP), Brasil.

José Roberto Guimarães

Doutor em Química pela Unicamp. Professor titular da Faculdade de Engenharia Civil, Arquitetura e Urbanismo da Unicamp - Campinas (SP), Brasil.

Pedro Sergio Fadini

Doutor em Ciências pela Unicamp - Campinas (SP), Brasil. Professor adjunto do Departamento de Química da Universidade Federal de São Carlos
\end{abstract}

(UFSCar) - São Carlos (SP), Brasil.

\section{Cintia Elena Nicolau}

Tecnóloga em Saneamento pela Unicamp - Campinas (SP), Brasil. Sanitarista Ambiental da Companhia de Saneamento Básico do Estado de São Paulo (SABESP) - São Paulo (SP), Brasil

\section{Resumo}

Nesta pesquisa, foram operados três filtros anaeróbios com tempo de detenção hidráulica nominal de nove horas, sendo o efluente gerado disposto nos leitos de quatro filtros de areia em distintas taxas de aplicações. No primeiro filtro de areia, foram aplicados $50 \mathrm{~L}$. $\mathrm{m}^{-2}$ uma vez por dia. No segundo, terceiro e quarto filtros, essa mesma carga foi disposta em 2, 3 e 4 horários, com aplicações espaçadas entre as 9h e as 16h, correspondendo às taxas de 100,150 e 200 L.m². dia-1. Após a passagem pelo leito de areia, o efluente era encaminhado para reatores de desnitrificação preenchidos com brita 1. Os filtros de areia apresentaram uma grande capacidade de nitrificação e, após a adição da fonte externa de carbono, o reator de desnitrificação que recebia uma única disposição diária de 50 L.m² propiciou uma diminuição na concentração de N-total de 43,5\%.

Palavras-chave: esgoto; tratamento; filtro anaeróbio; filtro de areia; nitrificação; desnitrificação.

\section{Abstract}

In this research, three anaerobic filters were operated with a 9 hour hydraulic detention time, and its effluent was disposed on four sand filters' bed in different application rates. On the first sand filter, $50 \mathrm{~L} . \mathrm{m}^{-2}$ were disposed once a day. On the second, the third and the fourth filters, the same load was disposed in twice, three and four times a day, distributed between 9 am and 4 pm, corresponding to rates of 100, 150 and $200 \mathrm{~L}^{-m^{-2}}$. $\mathrm{d}^{-1}$. After the sand filter, the effluent was conducted to the denitrification reactors filled up with grit. As result, the sand filters have shown a great nitrification capacity and, after the external carbon adding, the denitrification reactor, where $50 \mathrm{~L} . \mathrm{m}^{-2}$ was disposed a day, showed a decrease of $43.5 \%$ in $\mathrm{N}$-total concentration.

Keywords: wastewater; treatment; anaerobic filter; sand filter; nitrification; denitrification. 


\section{Introdução}

No emprego dos métodos simplificados para o tratamento de esgoto, um dos principais problemas que pode ocorrer é a contaminação da água subterrânea por nitrato. Segundo a USEPA (1993), o limite de $10 \mathrm{mg} \cdot \mathrm{L}^{-1}$ de $\mathrm{N}-\mathrm{NO}_{3}^{-}$para a água potável muitas vezes é superado em áreas rurais devido às contaminações ocasionadas pelos tanques sépticos.

Um dos meios para obter a remoção de compostos nitrogenados seria a nitrificação seguida pela redução biológica do nitrato para nitrogênio gasoso, conhecida como desnitrificação. A desnitrificação ocorre quando a disponibilidade de oxigênio molecular é baixa, levando as bactérias desnitrificantes a empregarem o nitrato e outras formas de nitrogênio como receptores de elétrons na respiração. Entre os fatores que afetam esse processo, podem ser mencionados: a concentração de oxigênio dissolvido, a temperatura, o pH e a qualidade e quantidade de fontes de carbono. Henze et al. (1997) constataram que o meio ideal para a desnitrificação tem um pH compreendido entre 7,0 e 9,0. Van Haandel e Marais (1999) citam que os valores ótimos abarcam a faixa que vai de 7,0 até 7,5 e quando menores que 6,0 e maiores que 8,5 reduzem grandemente a taxa dessa transformação bioquímica.

No que se refere ao oxigênio, a redução biológica do nitrato pode ser atingida mais rapidamente caso a concentração esteja próxima a zero, havendo um decréscimo da taxa quando ultrapassa 0,2 mg.L.-1 (DINÇER \& KARGI, 2000). Surampalli et al. (1997) apresentaram dados diferenciados ao constatarem que somente quando se superava $1,0 \mathrm{mg} \cdot \mathrm{L}^{-1}$ havia a inibição da desnitrificação, ressaltando que é fundamental determinar seus valores no interior do floco ou biofilme e não somente na fase líquida. Segundos esses autores, nos casos nos quais o ambiente apresenta baixas concentrações de oxigênio, a desnitrificação pode ser atribuída à existência de sítios anaeróbios nos quais formas oxidadas de nitrogênio atuam como receptoras de elétrons.

Quando a fonte de carbono remanescente no efluente do tratamento secundário apresenta uma concentração abaixo da requerida para a desnitrificação ou está em formas não suficientemente lábeis, há a necessidade da adição de algum composto orgânico passível de oxidação para viabilizar o processo. Essa fonte externa deve ter baixo custo, não ser tóxica, não causar danos ao ambiente e estimular a completa redução do nitrato sem a necessidade de adaptação da microflora. O composto suplementar ideal deve ainda ter custo baixo, ser facilmente disponível durante todo o ano, ser livre de nitrogênio e ter uma cinética adequada para o processo. Segundo Foresti et al. (2006), na desnitrificação é interessante o aproveitamento das substâncias provenientes dos processos anaeróbios, utilizando-as como doadores de elétrons para a redução do nitrato, principalmente em sistemas combinados anaeróbios e aeróbios.
Desse modo, neste estudo, foi avaliada a desnitrificação em reatores preenchidos com pedra britada, utilizando como fonte externa de carbono o efluente proveniente de filtros anaeróbios, enquanto que o efluente nitrificado era originário de filtros e areia.

\section{Metodologia}

Conforme descrito por TONETTI et al. (2010, 2012), a instalação experimental foi montada nas dependências da Faculdade de Engenharia Civil, Arquitetura e Urbanismo da Unicamp. O esgoto bruto aplicado nos filtros anaeróbios foi proveniente de algumas instalações da universidade, sendo bombeada uma parcela da sua vazão para uma caixa de 1.000 L localizada a 3,20 m de altura, mantida constantemente cheia e com circulação e transbordamento, em uma operação que permitiu a manutenção de uma vazão constante no sistema

A partir dessa caixa, o esgoto foi direcionado a três filtros anaeróbios. Cada um deles construído em aço inox com formato cilíndrico e volume total de 500 L. O fundo era cônico e separado da região ocupada pelo meio suporte por uma grade de bambu, funcionando como um compartimento para a distribuição da água residuária (TONETTI et al., 2010). Na Figura 1 é apresentada uma representação esquemática e fotos de um desses reatores.

O meio suporte foi constituído por anéis de bambu da espécie Bambusa tuldoides, cortados em tamanho de aproximadamente 0,05 m de comprimento, com diâmetro de 0,03 m (CAMARGO \& NOUR, 2001). Após o preenchimento dos reatores com esse material, uma média de $74,7 \pm 0,3 \%$ do volume interno era de vazios e a área superficial chegava a 91,8 $85,4 \mathrm{~m}^{2} \cdot \mathrm{m}^{-3}$ (Tonetti et al., 2012). A operação foi com fluxo ascendente e tempo de detenção hidráulica nominal de nove horas, sendo sua vazão controlada duas vezes ao dia.

\section{Filtros de areia}

Conforme descrito anteriormente por Tonetti et al. (2012), o efluente dos filtros anaeróbios foi direcionado a um recipiente de dosagem de 60 L que tinha em sua lateral uma graduação correspondente à carga de $50 \mathrm{~L} . \mathrm{m}^{-2}$. Da base desse recipiente, partia a tubulação que propiciou a disposição do efluente anaeróbio sobre a superfície dos quatro filtros de areia. Antes que o líquido encaminhado pela tubulação oriunda do recipiente de dosagem atingisse a superfície dos leitos de areia, havia seu choque com uma placa quadrada de madeira com 0,20 m de comprimento. $\mathrm{Na}$ colisão, formavam-se gotículas que eram uniformemente espalhadas sobre o leito.

Na construção dos filtros de areia, foram utilizadas caixas cilíndricas com estrutura de fibra de vidro e diâmetro interno de 


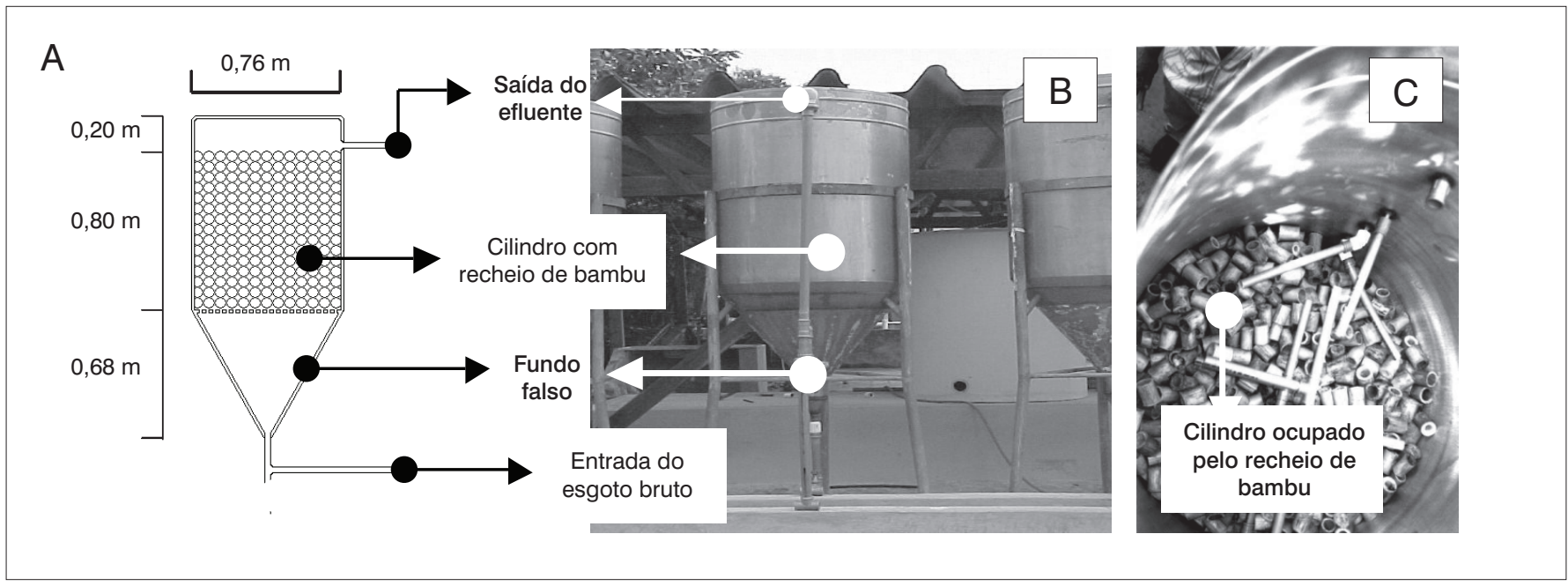

Figura 1 - Esquema de um filtro anaeróbio (A) e sua vista externa (B) e interna (C). Adaptado de Tonetti et al. (2010) e Tonetti et al. (2012).

1,00 $\mathrm{m}$, abertas na parte superior e com um pequeno orifício de 0,032 m na inferior, onde foi instalada a tubulação de saída do efluente (TONETTI et al., 2012). Para a composição do leito, foram empregadas três camadas estratificadas a partir da base do reator. A primeira tinha $0,20 \mathrm{~m}$ de profundidade e foi composta por brita 2, com diâmetro efetivo $\left(D_{10}\right)$ de $16,12 \mathrm{~mm}$, coeficiente de desuniformidade $\left(C_{D}\right)$ de 1,89 e coeficiente de vazios $\left(C_{v}\right)$ de $45,80 \pm 0,40 \%$. Logo acima, foi alocada uma camada constituída por brita 1 com $D_{10}$ igual a 7,51 mm, $C_{D}$ de 1,66 e $C_{v}$ de 44,08 $\pm 0,38 \%$ e 0,05 m de profundidade (TONETTI et al., 2012). A brita foi utilizada para sustentar a areia, impedindo o arraste para fora da estrutura do sistema. Na Figura 2, está apresentado o esquema de um filtro de areia com a disposição das camadas.

O leito de areia tinha uma profundidade de 0,75 m, que segundo Tonetti et al. (2010) foi o valor que se mostrou mais adequado para o tratamento. A areia empregada foi a popularmente denominada de média, classificada de acordo com procedimento apresentado pela NBR 6502 (ABNT, 1995), com um diâmetro efetivo de 0,18 mm, coeficiente de desuniformidade de 3,14 e coeficiente de vazios de $28,6 \pm 0,9 \%$.

Conforme orientação de Tonetti et al. (2012), para a ampliação da aeração do leito, foi instalado na lateral de cada filtro um tubo com 0,050 m de diâmetro interno (Figura 2). No interior do reator, esse tubo penetrava na camada de brita 2 constituindo uma estrutura com formato de cruz, tendo em toda a sua extensão superior, inferior e laterais perfurações com diâmetro de 0,020 m espaçadas por $0,020 \mathrm{~m}$.

\section{Reatores de desnitrificação}

O efluente originário de cada um dos filtros de areia foi imediatamente direcionado pela ação da gravidade para seus respectivos reatores de desnitrificação, onde entrava pela parede lateral, tal como pode ser observado na Figura 3. Na construção desses reatores, foram utilizadas caixas cilíndricas com estrutura de fibra de vidro e diâmetro interno de $1,00 \mathrm{~m}$. O leito, que atuou como suporte para as bactérias desnitrificantes, tinha profundidade de 0,30 m e foi composto pela mesma brita 1 adotada nas bases dos filtros de areia. Todos esses reatores foram cobertos com uma lona plástica, minimizando a troca gasosa entre o líquido e a atmosfera.

A saída do efluente ocorria pelo centro da parte inferior, sendo que a tubulação acompanhava a lateral do reator até a altura

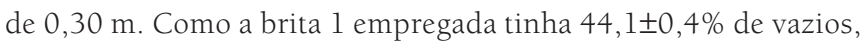
acabava garantindo a permanência de aproximadamente 0,104 $\mathrm{m}^{3}$ de líquido no interior do cilindro.

\section{Aspectos operacionais}

Buscando uma adequada comparação de resultados, na presente pesquisa manteve-se a mesma sistemática operacional adotada por Tonetti et al. (2012). A operação dos filtros anaeróbios ocorreu com fluxo ascendente e tempo de detenção hidráulica nominal de 9 horas. O efluente proveniente desses reatores foi aplicado entre as segundas e as sextas-feiras sobre as superfícies dos leitos de areia em cargas de 50 L.m-2. Para cada um dos filtros de areia, esse valor foi disposto em uma particular frequência de aplicação e em um curto intervalo de tempo, correspondente ao rápido esvaziamento do recipiente de dosagem. Essa breve disposição buscou simular o uso da válvula ou da caixa de descarga, quando o sistema acaba sendo mais exigido.

No primeiro filtro (FAl), foi empregada a carga de $50 \mathrm{~L} \cdot \mathrm{m}^{-2}$ uma vez por dia, aplicada às 9 h. No segundo filtro (FA2), essa carga foi disposta duas vezes ao dia, com intervalo de sete horas, 


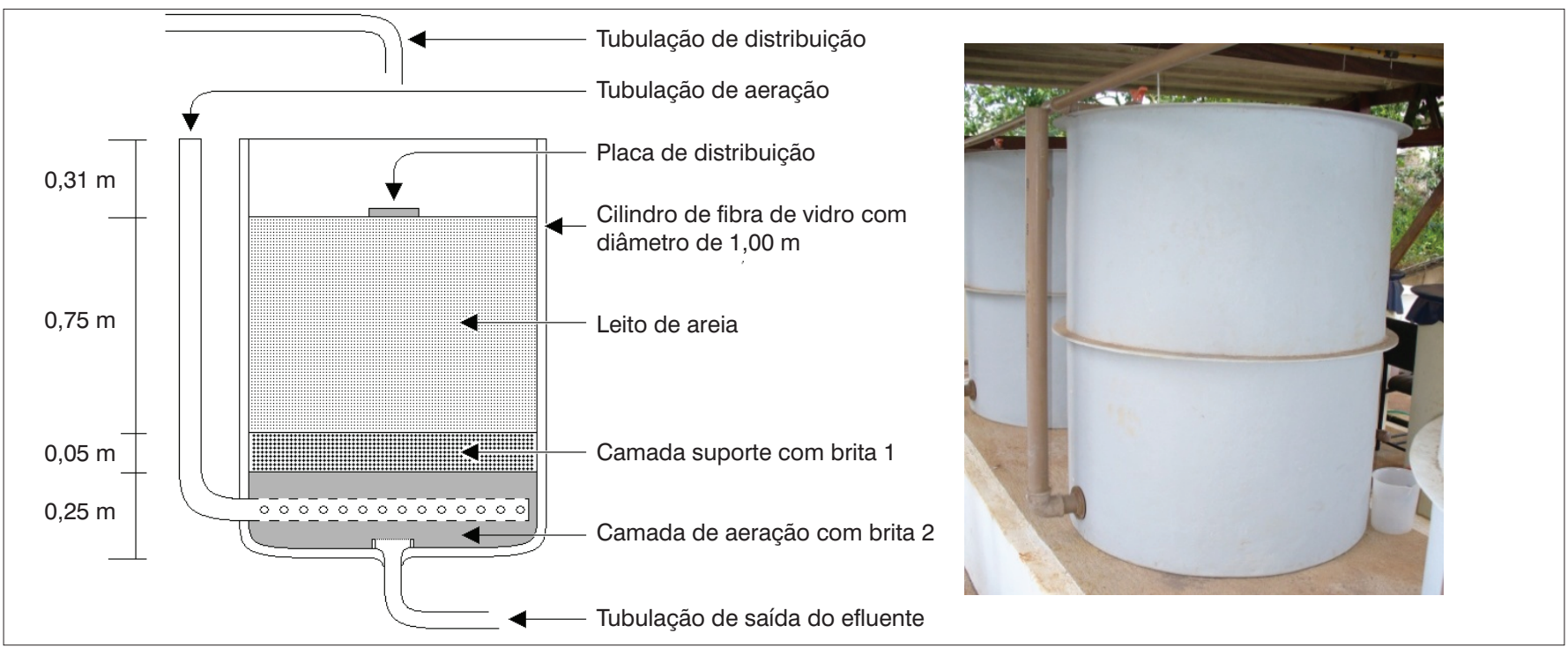

Figura 2 - Esquema e foto dos filtros de areia. Adaptado de Tonetti et al. (2012).

ou seja, às 9 h e às $16 \mathrm{~h}$. No terceiro filtro (FA3), foram três aplicações diárias: às 9h, 12 h30 e 16h. Finalmente, no quarto filtro (FA4), as aplicações foram realizadas às 9h, 11h20, $13 \mathrm{~h} 40$ e $16 \mathrm{~h}$ (TONETTI et al., 2012).

\section{Adição de fonte externa de carbono}

A partir da avaliação da necessidade de se empregar uma fonte externa de carbono, tendo em vista criar condições adequadas para a redução biológica do nitrogênio, foram aplicados $20 \mathrm{~L}$ de efluente anaeróbio nos reatores de desnitrificação por meio do tubo ilustrado na Figura 3. As aplicações foram sempre efetuadas às $19 \mathrm{~h}$ e ocorriam em um curto intervalo de tempo, sendo que todos os quatro reatores recebiam diariamente uma única aplicação de líquido.

\section{Coleta das amostras e análises laboratoriais}

As seguintes amostras foram coletadas semanalmente, toda terça-feira, a partir do sistema em estudo: esgoto bruto e efluente dos filtros anaeróbios, dos quatro filtros de areia e dos quatro reatores de desnitrificação. Na Figura 4, está exposto um esquema que ilustra todos os pontos de coleta, assim como estão definidas as denominações de cada um dos reatores empregados na pesquisa.

A amostragem do esgoto bruto foi realizada imediatamente antes de sua entrada nos filtros anaeróbios enquanto que a coleta unificada do efluente desses reatores dava-se anteriormente a sua aplicação nos leitos de areia (TONETTI et al., 2012). Os efluentes dos filtros de areia foram coletados antes de sua chegada aos respectivos reatores de desnitrificação. Por fim, os líquidos originários dessa última etapa do tratamento foram obtidos após as
A

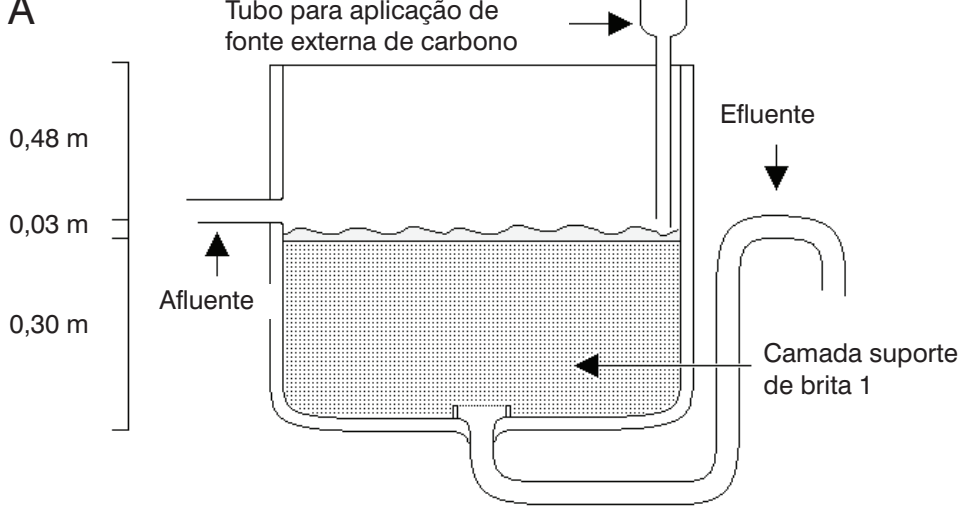

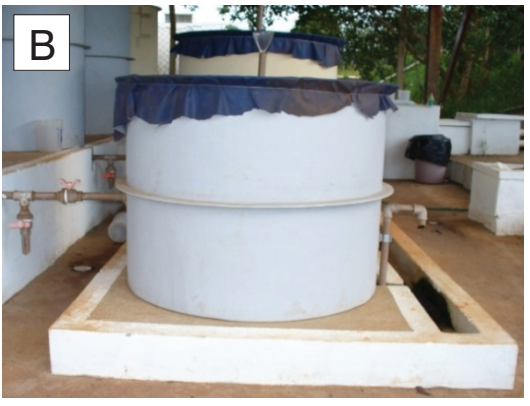

Figura 3 - Esquema (A) e foto (B) dos reatores de desnitrificação. 


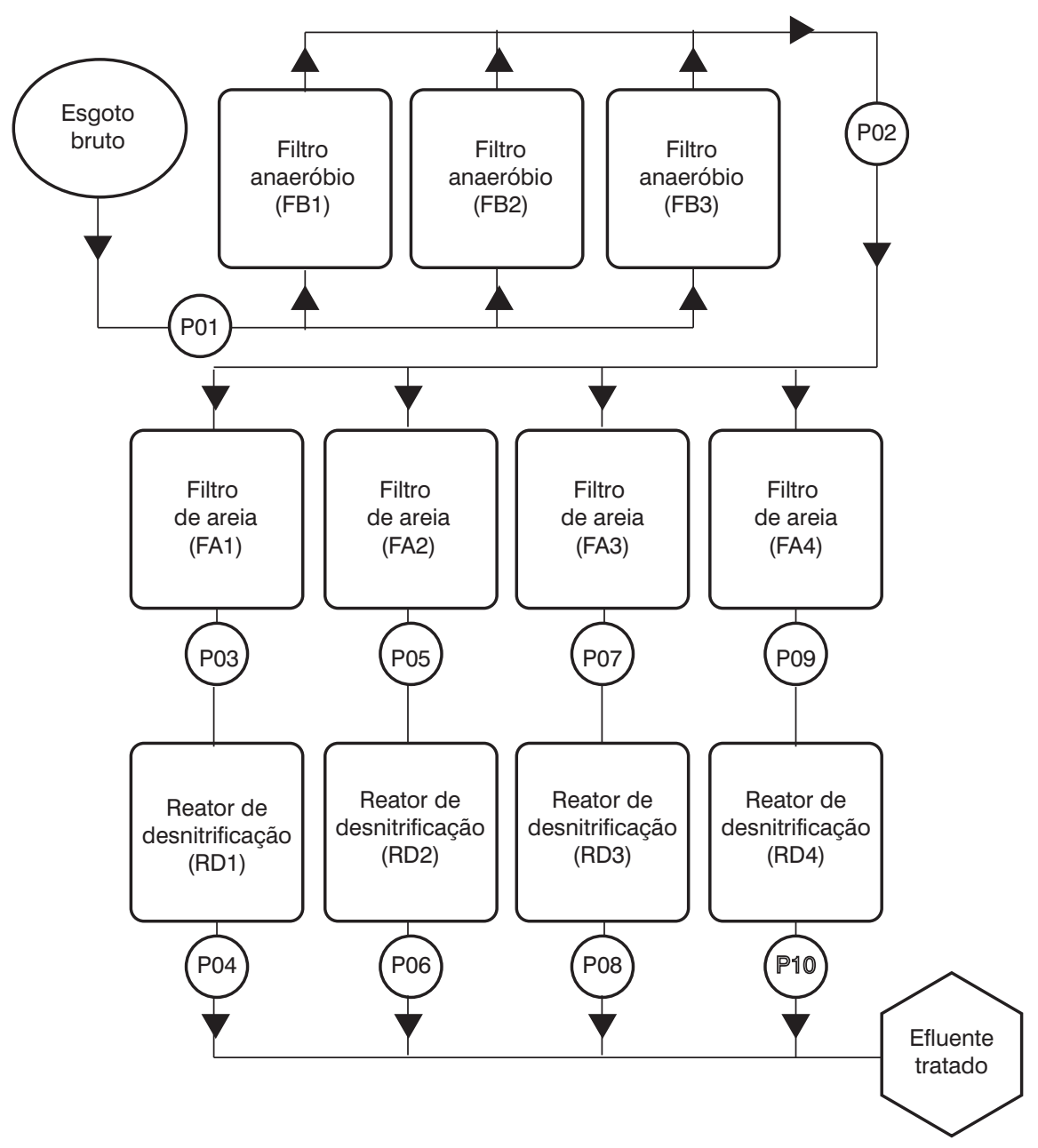

Figura 4 - Esquema dos pontos de coleta e denominações dos reatores.

tubulações de saída. O início da amostragem dos efluentes dos filtros de areia e dos reatores de desnitrificação ocorria após a última disposição diária, de forma pontual, quando existia claramente o aumento da vazão de saída do líquido.

As análises das amostras coletadas foram realizadas no Laboratório de Saneamento da Faculdade de Engenharia Civil, Arquitetura e Urbanismo da Unicamp (LABSAN), seguindo as recomendações contidas no Standard Methods for the Examination of Water and Wastewater (APHA et al., 2005). Especificamente quanto aos compostos nitrogenados (nitrogênio amoniacal, nitrito e nitrato), adotou-se o método FIA (Flow Injection Analysis), conforme exposto por Faria e Pasquini (1991).

Os resultados obtidos foram submetidos a um tratamento estatístico fazendo-se uso do Programa Bioestat 5.0. Os dados foram analisados quanto a variância e as médias comparadas por meio do teste de Kruskal-Wallis no nível de 5\% (p<0,05).

\section{Resultados}

\section{pH e alcalinidade total}

Nas primeiras semanas de operação dos filtros de areia, conforme pode ser constatado pela análise da Figura 5, os efluentes gerados apresentaram valores muito baixos de $\mathrm{pH}$, chegando a médias próximas a 4,0. Esse comportamento pode ser fruto da nitrificação propiciada pelos leitos de areia, que garantiram uma eficiência para tal processo sempre superior a 70,1\% (Tabela. 1).

$\mathrm{Na}$ nitrificação, segundo Metcalf e Eddy (2003), para cada 1,00 g de $\mathrm{N}-\mathrm{NH}_{4}{ }^{+}$convertido ocorre o consumo de 4,25 g de $\mathrm{O}_{2}$, formando 0,16 g de novas células a partir da utilização de 0,08 g de carbono inorgânico. Como consequência, há a diminuição em $7,07 \mathrm{~g}$ da alcalinidade expressa como $\mathrm{CaCO}_{3}$. Na presente pesquisa, isso acarretou o completo consumo da alcalinidade presente no meio, criando condições para a acentuada diminuição do $\mathrm{pH}$ nos efluentes dos filtros de areia (Figura. 5). Esse processo 
de nitrificação e consumo de alcalinidade também foi observado por Tonetti et al. (2012).

Todos os efluentes dos reatores de desnitrificação apresentaram valores significativamente superiores de $\mathrm{pH}(\mathrm{p}<0,05)$ quando comparados aos respectivos filtros de areia. Uma explicação para esse comportamento pode estar relacionada à influência do leito de brita, a qual tem compostos com características básicas que, possivelmente, estavam se dissolvendo no meio líquido. Tal hipótese é reforçada pelo fato de que o reator de desnitrificação 1 (RD1), que recebeu uma menor taxa de aplicação diária, acabava sofrendo uma maior influência da ação do leito de brita e, consequentemente, apresentou o maior valor médio de $\mathrm{pH}$. No entanto, é esperado que essa interferência seja minimizada no decorrer da aplicação do afluente, ocasionando a geração de uma solução com menor valor de $\mathrm{pH}$, tal como ocorreu nos outros reatores.

Cabe destacar que a brita utilizada nos filtros de areia e nos reatores de desnitrificação apresentava características semelhantes às tradicionalmente utilizadas na construção civil, com a seguinte composição: $85 \%$ de granito e gnaisse; $10 \%$ de calcário e dolomito e $5 \%$ de basalto e diabásio. Assim, o calcário pode ter sido um dos possíveis compostos que propiciaram a manutenção da alcalinidade no efluente dos reatores de desnitrificação na etapa inicial da pesquisa.

De modo geral, verifica-se que, quanto ao $\mathrm{pH}$, os efluentes dos filtros de areia e reatores de desnitrificação apresentaram uma tendência a uma qualidade imprópria para o lançamento em corpos hídricos (BRASIL, 2005, BRASIL, 2011). Além disso, também seriam inadequados para a desnitrificação, visto que Henze et al. (1997), Surampalli et al. (1997) e van Haandel e Marais
(1999) citam que os valores ótimos para esse processo bioquímico são superiores a 6,0.

Tendo-se em vista a adequação quanto a esse parâmetro, tal como realizado por Tonetti et al. (2012), adicionou-se $100 \mathrm{~mL}$ de uma solução de carbonato de sódio (barrilha) com concentração de 120 g. $L^{-1}$ em conjunto com cada disposição da taxa hidráulica de 50 L.m ${ }^{-2}$. dia ${ }^{-1}$ de efluente anaeróbio nos filtros de areia. Como resultado dessa ação, houve o aumento da média dos valores de $\mathrm{pH}$ nos efluentes dos filtros de areia para $7,5 \pm 0,3$; enquanto que nos reatores de desnitrificação chegou-se a 7,5 $\pm 0,2$, não existindo entre ambos os valores diferenças significativas $(p<0,05)$.

\section{Série de Nitrogênio}

Tal como encontrado por Tonetti et al. (2012), desde o início da operação dos filtros de areia ocorreu um profundo processo de transformação bioquímica, que ocasionou um acentuado incremento nas concentrações de nitrato e a diminuição dos valores de N-NTK. Conforme pode ser percebido pela análise da Tabela 1, a nitrificação atingiu $89,2 \pm 8,8 \%$ no FAl e 70,1 $\pm 9,1 \%$ no FA4 Após a disposição de carbonato de sódio na superfície dos filtros de areia concomitantemente com o efluente anaeróbio para a cor-

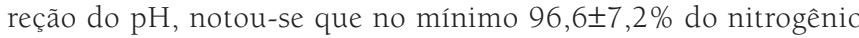
total do efluente dos filtros de areia era composto por nitrato.

A nitrificação do efluente anaeróbio possibilitou o cumprimento da legislação brasileira (BRASIL, 2005) quanto à concentração de nitrogênio amoniacal no lançamento do efluente, mas, por outro lado, poderia tê-lo comprometido no que tange ao nitrato, visto que essa norma legal estabelece que nos corpos de

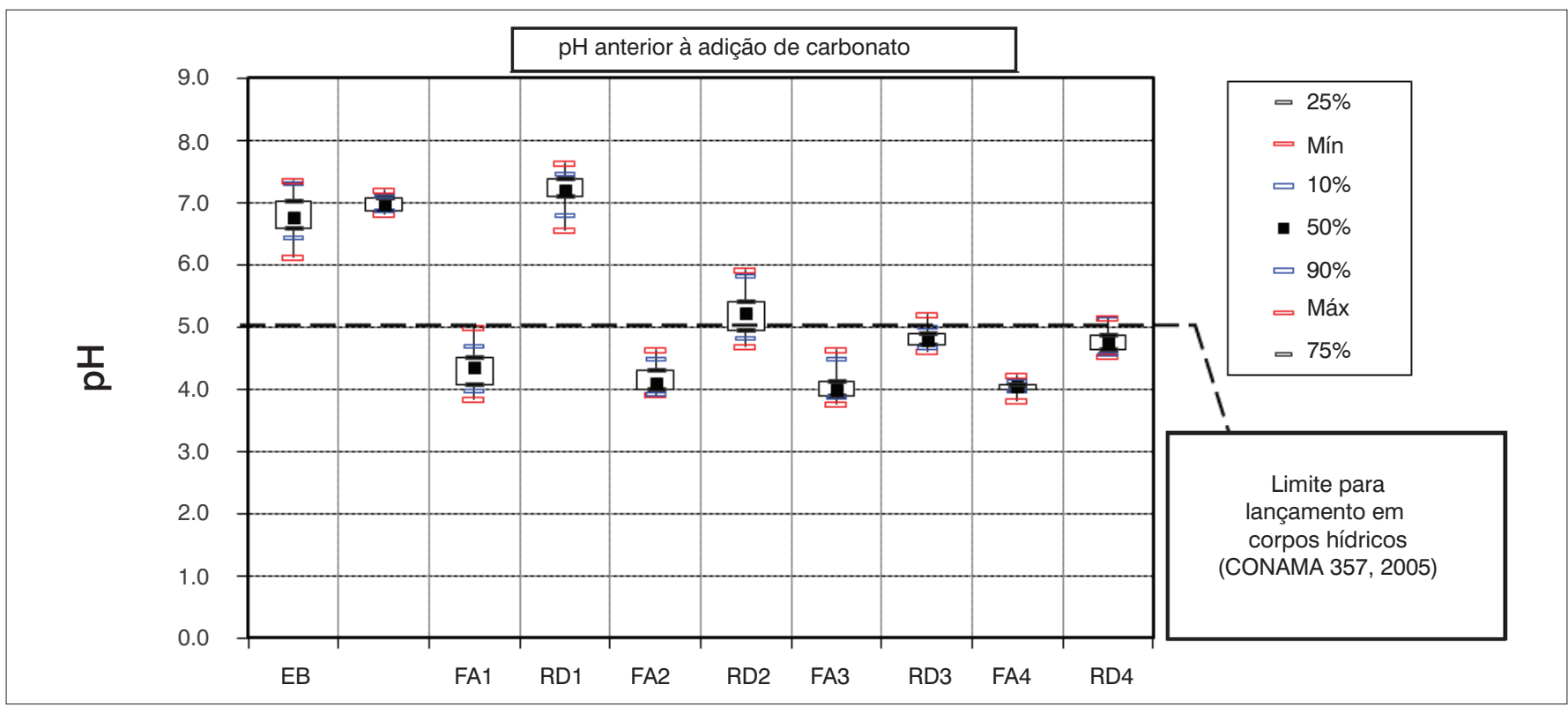

Figura 5 - Média do pH do esgoto bruto e efluente dos filtros anaeróbios, filtros de areia (FA1, FA2, FA3 e FA4) e reatores de desnitrificação (RD1, RD2, RD3 e RD4). 
Tabela 1 - Concentrações médias de nitrogênio total, nitrogênio total Kjeldahl e N-nitrato presentes no efluente dos filtros de areia e reatores de desnitrificação.*

\begin{tabular}{|c|c|c|c|c|c|c|}
\hline Reator & \multicolumn{2}{|c|}{$\mathrm{N}-\mathrm{NO}_{3}^{-}\left(\mathrm{mg} \cdot \mathrm{L}^{-1}\right)$} & \multicolumn{2}{|c|}{$\mathrm{N}-\mathrm{NO}_{3}^{-}(\%)$} & \multicolumn{2}{|c|}{$\mathrm{N}$-Total efluente (mg. $\left.\mathrm{L}^{-1}\right)$} \\
\hline \multicolumn{7}{|c|}{ Filtros anaeróbios e filtros de areia (antes da adição de $\mathrm{Na}_{2} \mathrm{CO}_{3}$ ) } \\
\hline Filtros anaeróbios & \multicolumn{2}{|c|}{$0,0 \mathrm{a}$} & \multicolumn{2}{|c|}{0,0} & \multicolumn{2}{|c|}{$42,8 \mathrm{a}$} \\
\hline FA1 & \multicolumn{2}{|c|}{$37,4 \mathrm{~b}$} & \multicolumn{2}{|l|}{89,2} & \multicolumn{2}{|c|}{$41,6 \mathrm{a}$} \\
\hline FA2 & \multicolumn{2}{|c|}{$31,5 \mathrm{bc}$} & \multicolumn{2}{|l|}{82,6} & \multicolumn{2}{|c|}{$37,5 \mathrm{a}$} \\
\hline FA3 & \multicolumn{2}{|c|}{$28,7 \mathrm{c}$} & \multicolumn{2}{|l|}{79,0} & \multicolumn{2}{|c|}{$35,6 \mathrm{a}$} \\
\hline FA4 & \multicolumn{2}{|c|}{$25,7 \mathrm{c}$} & \multicolumn{2}{|l|}{70,1} & \multicolumn{2}{|c|}{$34,8 \mathrm{a}$} \\
\hline \multicolumn{7}{|c|}{ Filtros de areia (após a adição de $\mathrm{Na}_{2} \mathrm{CO}_{3}$ ) } \\
\hline FA1 & \multicolumn{2}{|c|}{$57,1 \mathrm{~b}$} & \multicolumn{2}{|c|}{98,8} & \multicolumn{2}{|c|}{$58,0 \mathrm{a}$} \\
\hline FA2 & \multicolumn{2}{|c|}{$50,7 \mathrm{~b}$} & \multicolumn{2}{|l|}{97,8} & \multicolumn{2}{|c|}{52,3 a } \\
\hline FA3 & \multicolumn{2}{|c|}{$56,5 b$} & \multicolumn{2}{|l|}{96,8} & \multicolumn{2}{|c|}{58,8 a } \\
\hline FA4 & \multicolumn{2}{|c|}{$45,2 \mathrm{~b}$} & \multicolumn{2}{|l|}{96,6} & 47,3 & \\
\hline & & $\mathrm{Re}$ & nitrificação & & & \\
\hline & N-Total Efluente & & Efluente & & DQN & \\
\hline Reator & $\begin{array}{l}\text { dos filtros de areia } \\
\left(\mathrm{mg} \cdot \mathrm{L}^{-1}\right)\end{array}$ & $\begin{array}{l}\text { N-NTK } \\
\left(\mathrm{mg} \cdot \mathrm{L}^{-1}\right)\end{array}$ & $\begin{array}{l}\text { N-Nitrato } \\
\left(\mathrm{mg} \cdot \mathrm{L}^{-1}\right)\end{array}$ & $\begin{array}{l}\mathrm{N}-\text { Total } \\
\left(\mathrm{mg} \cdot \mathrm{L}^{-1}\right)\end{array}$ & $\mathrm{N}-\mathrm{NO}_{3}$ & N-Total (\%) \\
\hline & & tes da ad & ${ }_{3}$ nos filtros & & & \\
\hline RD1 & $41,6 \mathrm{a}$ & $0,0 a^{*}$ & $45,8 \mathrm{a}^{\star}$ & $45,8 a^{\star}$ & $2,2 a^{*}$ & $* *$ \\
\hline RD2 & $37,5 \mathrm{a}$ & $1,6 a^{*}$ & $42,0 \mathrm{ab}^{*}$ & $43,6 a^{*}$ & $2,4 a^{*}$ & ** \\
\hline RD3 & $35,6 \mathrm{a}$ & $3,5 b^{*}$ & $36,3 b c^{*}$ & $39,8 a^{*}$ & $2,5 a^{*}$ & ** \\
\hline $\mathrm{RD} 4$ & $34,8 \mathrm{a}$ & $6,2 c^{*}$ & $30,5 c^{*}$ & $36,7 a^{*}$ & $3,5 a^{*}$ & $\star *$ \\
\hline & & pós a adic & nos filtros $c$ & & & \\
\hline RD1 & $65,2 a^{*}$ & $0,0 a^{*}$ & $68,4 a^{*}$ & $68,4 a^{\star}$ & $0,9 a^{*}$ & ** \\
\hline RD2 & $59,5 a^{*}$ & $1,2 a b^{*}$ & $64,1 \mathrm{a}^{\star}$ & $65,3 a^{*}$ & $1,0 a^{*}$ & ** \\
\hline RD3 & $65,8 a^{*}$ & $3,1 b^{*}$ & $62,1 a^{*}$ & $65,2 a^{*}$ & $0,9 a^{*}$ & ** \\
\hline RD4 & $56,0 a^{*}$ & $3,2 b^{*}$ & $58,5 a^{*}$ & $61,7 a^{*}$ & $1,3 a^{*}$ & $* *$ \\
\hline & & pós a adic & efluente an & & & \\
\hline RD1 & $53,1 a^{*}$ & $8,6 a^{*}$ & $21,4 a^{*}$ & $30,0 a^{*}$ & $2,9 a^{*}$ & $43,5 \mathrm{a}$ \\
\hline RD2 & $44,8 a^{*}$ & $7,3 a b^{*}$ & $34,1 \mathrm{ab}^{*}$ & $41,4 \mathrm{ab}^{*}$ & $2,0 a b^{*}$ & $7,6 \mathrm{~b}$ \\
\hline RD3 & $51,7 a^{*}$ & $5,8 b^{*}$ & $50,8 b^{*}$ & $56,6 b^{\star}$ & $1,6 b^{*}$ & $* *$ \\
\hline RD4 & $32,6 a^{*}$ & $4,2 c^{*}$ & $51,7 b^{*}$ & $55,9 b^{*}$ & $1,9 b^{*}$ & $\star *$ \\
\hline
\end{tabular}

*Médias seguidas pela mesma letra minúscula na vertical não diferem entre si $(p<0,05)$. **Não foi caracterizada a remoção.

água de classe 1, 2 e 3 o valor limite para esse composto deve ser de $10,0 \mathrm{mgL}^{-1}$.

Conforme apresentado na Tabela 1, os reatores de desnitrificação empregados para atenuarem as altas concentrações de nitrato não apresentaram nenhum processo expressivo para a sua remoção anterior à adição da fonte externa de carbono. Uma explicação para esse comportamento, caracterizado como o período antecedente à disposição do composto alcalino, pode ser os baixos valores de pH (Figura 5), inadequados à atuação das bactérias desnitrificantes.

Após a correção do pH da massa líquida, também não ocorreu a desnitrificação. Uma hipótese para tal desempenho seriam as baixas concentrações de matéria orgânica que adentravam os reatores, que no caso do RDl atingiu a média expressa como demanda química de oxigênio (DQO) de somente $30 \pm 14 \mathrm{mg} \cdot \mathrm{O}_{2} \cdot \mathrm{L}^{-1}$ (Tabela 2). Outro aspecto fortemente inadequado para o processo foi a existência de uma alta concentração de oxigênio dissolvido, visto que os efluentes dos reatores apresentaram médias superiores a 4,0 mg. $\mathrm{L}^{-1}$ de oxigênio dissolvido (OD), um receptor de elétrons mais eficiente em termos de liberação de energia do que o nitrato (Figura 6).

\section{Adição de fonte externa de carbono}

A adição de efluente dos filtros anaeróbios, por meio de um tubo externo (Figura 3), foi iniciada visando ao fornecimento de 
Tabela 2 - Valores médios de demanda química de oxigênio bruta e de remoção nos filtros de areia em relação ao efluente dos filtros anaeróbios e nos reatores de desnitrificação em relação ao respectivo filtro de areia. *

\begin{tabular}{|c|c|c|c|}
\hline Reator & $\mathrm{DQO}_{\text {Bruta }}$ média $\left(\mathrm{mg} \cdot \mathrm{O}_{2} \cdot \mathrm{L}^{-1}\right)$ & Remoção (\%) & Sólidos suspensos totais (mg. $\left.\mathrm{L}^{-1}\right)$ \\
\hline \multicolumn{4}{|c|}{ Filtros de areia } \\
\hline $\mathrm{FA} 1$ ** & 66 & 72 & 14 \\
\hline $\mathrm{FA} 2^{\star \star}$ & 62 & 75 & 21 \\
\hline $\mathrm{FA}^{* *}$ & 68 & 73 & 13 \\
\hline $\mathrm{FA} 4 * \star$ & 75 & 72 & 15 \\
\hline \multicolumn{4}{|c|}{ Reatores de desnitrificação (antes da adição da fonte externa de carbono) } \\
\hline RD1 & $30 a^{*}$ & 54 & $12 \mathrm{c}$ \\
\hline $\mathrm{RD} 2$ & $37 a b^{*}$ & 43 & $12 \mathrm{c}$ \\
\hline RD3 & $46 \mathrm{bc}^{*}$ & 33 & $8 \mathrm{c}$ \\
\hline RD4 & $57 c^{*}$ & 25 & $10 \mathrm{c}$ \\
\hline \multicolumn{4}{|c|}{ Reatores de desnitrificação (após a adição da fonte externa de carbono) } \\
\hline RD1 & $50 b^{*}$ & 21 & $2 a^{*}$ \\
\hline RD2 & $37 b^{*}$ & 24 & $2 a^{*}$ \\
\hline RD3 & $41 b^{*}$ & 24 & $4 b^{*}$ \\
\hline RD4 & $44 b^{*}$ & 20 & $4 b^{*}$ \\
\hline
\end{tabular}

*Médias seguidas pela mesma letra minúscula na vertical não diferem entre si $(p<0,05)$. **Médias para todo o período da pesquisa.

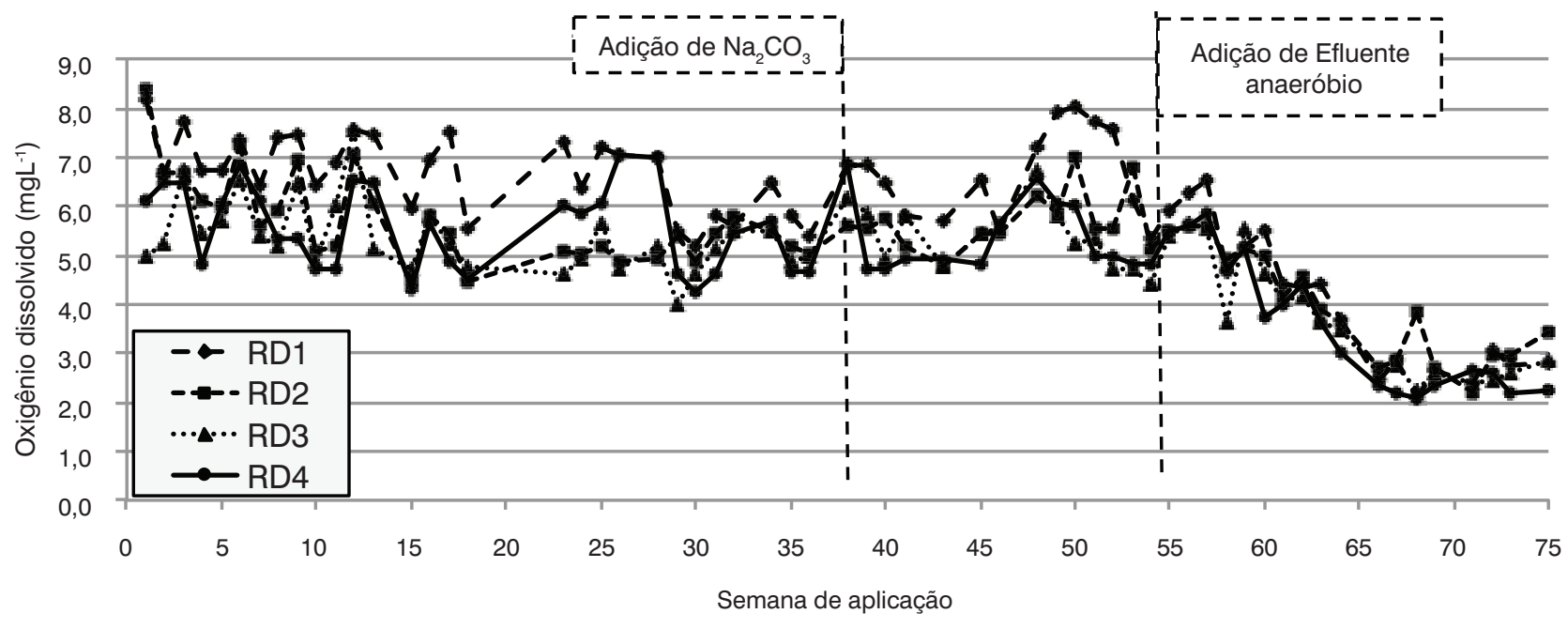

Figura 6 - Concentração de oxigênio dissolvido nos efluentes dos reatores de desnitrificação.

uma fonte externa de carbono e à criação de condições de anaerobiose propícias para a redução biológica do nitrogênio. No princípio, sempre às 19h, foram aplicados 4 L desse líquido em cada um dos reatores de desnitrificação, sendo que tal valor foi aumentado em $4 \mathrm{~L}$ a cada semana até atingir, na 62 a semana, $20 \mathrm{~L}$. Adotou-se esse volume final para garantir uma concentração de nitrogênio amoniacal no efluente do RDl que não ultrapassasse o limite estabelecido pela legislação brasileira (BRASIL, 2005) quanto à concentração de $\mathrm{N}_{-} \mathrm{NH}_{4}{ }^{-}$em lançamento de efluentes, que é de $20 \mathrm{mg} \cdot \mathrm{L}^{-1}$.

Como resultado, no RD1 a concentração de nitrogênio amoniacal saltou para $8,6 \pm 0,4 \mathrm{mg} . \mathrm{L}^{-1}$ (Tabela 1 ), porém em todos os reatores os valores não superaram o limite estabelecido para o lançamento em corpos hídricos (BRASIL, 2005). No que tange à diminuição da concentração de nitrogênio total encontrada no reator de desnitrificação RD1, nota-se uma significativa diferenciação $(p<0,05)$ entre os valores de N-total afluente e efluente. 
A queda na concentração desse composto no efluente do RD1 atingiu 43,5 $\pm 7,3 \%$, enquanto que no reator de desnitrificação 2 (RD2) foi bastante inferior, sendo de 7,5 $\pm 17,4 \%$. Nos outros dois reatores, mesmo recebendo semelhante aporte de nitrogênio a partir do efluente anaeróbio, os dados foram superiores aos obtidos no afluente, não apontando para a desnitrificação.

Tais resultados demonstraram que a frequência de disposição adotada nos filtros de areia influenciou a eficiência dessa transformação bioquímica, provavelmente devido à diminuição do tempo de residência do líquido no interior do reator de desnitrificação, acarretando um menor contato com a cultura biológica. Especificamente para o RD1, a coleta ocorria às $9 \mathrm{~h}$ do dia seguinte à disposição da fonte externa de carbono. No caso, a amostra obtida era originária da interação do efluente anaeróbio com a massa líquida retida no reator e com a cultura biológica por um período de 14 horas. Recordando que a aplicação do efluente anaeróbio no reator de desnitrificação ocorria sempre às $19 \mathrm{~h}$.

No conjunto 2 (Figura 4), havia uma nova aplicação de efluente anaeróbio nos filtros de areia às 9h, cuja água residuária passava pelo tratamento no leito de areia (Filtro de Areia 2 FA2) e, logo após, adentrava o reator RD2. Desse modo, existia o descarte de uma massa líquida que havia sido parcialmente desnitrificada para a entrada de outra com altos valores de nitrato, que possivelmente não permaneciam um tempo apropriado para a interação com a cultura biológica, além de não ter uma fonte de carbono com concentração suficientemente elevada. Às 16h, após outra aplicação de efluente anaeróbio no filtro de areia, a amostra acabava coletada sob essas condições. Nos reatores de desnitrificação 3 e 4 (RD3 e RD4), o comprometimento era ainda maior, visto que entre a aplicação inicial e a final havia outras intermediárias, ocasionando a entrada de uma maior carga de efluente nitrificado na diluição da fonte de carbono empregada e na diminuição do tempo de residência do líquido no reator.

Ao comparar os dados obtidos para a concentração de N-nitrato com o limite estabelecido pela legislação brasileira, nota-se que mesmo após a passagem pelo reator de desnitrificação não havia a geração de um efluente abaixo de 10,0 mg..-1

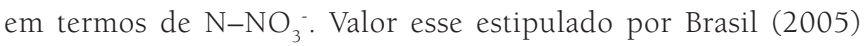
como o máximo permitido em corpos de água de classes 1,2 e 3. Contudo, tal limite não se refere à concentração do efluente lançado, mas àquela presente no corpo hídrico após a sua diluição. Desse modo, o tratamento gerado pelo reator de desnitrificação permitiria que, em um determinado corpo receptor, fosse lançado maior volume de água residuária tratada, sem que se infringisse a legislação brasileira.

Confrontando-se os valores encontrados com os recomendados pela Organização das Nações Unidas para Agricultura e Alimentação (FAO, 1994) para a qualidade da água a ser empregada na agricultura, percebe-se que a redução biológica do nitrato propiciada pelo reator de desnitrificação RDl foi extremamente benéfica. O efluente do filtro de areia FAl, que tinha concentração de $\mathrm{N}_{-} \mathrm{NO}_{3}$ - superior a 50,0 mg. $\mathrm{L}^{-1}$, levando-o a ter um grau severo de restrição ao uso, passou a ter uma média inferior a $30 \mathrm{mg} . \mathrm{L}^{-1}$, tornando-o com grau leve ou moderado para o emprego em alguma prática agrícola.

Quanto à razão DQO/N-NO $\mathrm{N}_{3}$ apresentada na Tabela 1 , os dados podem ser comparados aos obtidos por Çeçen e Gonenç (1995). Segundo os autores, evita-se a deficiência de carbono orgânico no processo caso essa razão esteja próxima a 5 . No mesmo sentido, van Rijn et al. (2006) afirmaram que o valor dessa relação para a completa redução do nitrato varia entre 3 e 6 . Dessa forma, percebe-se que, em praticamente todo o período da pesquisa, os reatores de desnitrificação operaram com uma razão entre matéria orgânica e nitrato muito aquém daquela definida na literatura como ótima para as bactérias desnitrificantes.

Anterior à adição da fonte externa de carbono, a razão $\mathrm{DQO} / \mathrm{N}-\mathrm{NO}_{3}$ oscilou entre as médias de 0,9 e 3,5, tendo uma queda após a correção do pH. Essa alteração foi acarretada pelo amadurecimento dos filtros de areia, que levou a diminuição dos valores de DQO, combinada com a ampliação da nitrificação pela adição do composto alcalino. Na continuidade da pesquisa, em seguida à adição da fonte de carbono, ocorreu um significativo aumento $(\mathrm{p}<0,05)$ para a razão entre os dados de matéria orgânica e de nitrato. Porém, mesmo no reator RD1, que teve o maior acréscimo relativo de DQO, a razão atingiu somente 2,9. Nesse caso, apesar de o meio ser inadequado, existiu um processo expressivo de desnitrificação, possivelmente resultante da formação de zonas com maiores concentrações de matéria orgânica, as quais tinham altos valores para a razão. DQO/N-NO . Cabe a observação de que a fonte de carbono empregada teve a labilidade diminuída, uma vez que os compostos facilmente degradáveis foram removidos no filtro anaeróbio.

Her e Huang (1995) afirmam que uma relação entre carbono e nitrogênio abaixo da ideal levaria ao acúmulo de nitrito, devido à carência do doador de elétrons implicar impedimento da completa desnitrificação. Nesse caso, os dados da presente pesquisa não corroboram a afirmação desse autor, visto que as concentrações de $\mathrm{N}-\mathrm{NO}_{2}$ presentes tanto no efluente dos filtros de areia como no dos reatores de desnitrificação sempre estiveram abaixo de 1,0 mg. L $^{-1}$. Por sua vez, van Rijn et al. (2006) descrevem que uma limitação de carbono resultaria no acúmulo de produtos intermediários, principalmente $\mathrm{N}_{2} \mathrm{O}$ e NO . Infelizmente, esses gases não foram avaliados neste trabalho.

Com a adição da fonte externa de carbono, foi observado um ligeiro acréscimo na alcalinidade do reator de desnitrificação RD1 (dados não apresentados), quando comparado ao filtro de areia FAl. Esse desempenho pode ser fruto da redução bioquímica do nitrato, no entanto não foi possível determinar se os resultados 
confirmavam a afirmação de van Rijn et al. (2006). Para esse autor, cada $1,00 \mathrm{mg}$ de $\mathrm{N}_{-} \mathrm{NO}_{3}{ }^{-}$reduzido a $\mathrm{N}_{2}$ leva ao aumento da alcalinidade em 3,57 mg. $\mathrm{L}^{-1}$ quanto ao $\mathrm{CaCO}_{3}$.

Um fator que dificulta a obtenção dessa correlação seria a nitrificação existente no reator de desnitrificação, uma vez que houve uma redução na concentração do nitrogênio amoniacal adicionado conjuntamente com o efluente anaeróbio. Combinado a isso, também existiu a presença de valores de alcalinidade na própria fonte externa de carbono adotada e também houve a impossibilidade de se afirmar categoricamente que todo o nitrato desnitrificado foi transformado em $\mathrm{N}_{2}$ ou em algum composto intermediário.

\section{Demanda química de oxigênio e oxigênio dissolvido}

Tal como obtido por Tonetti et al. (2012), quanto à DQO nos efluentes dos filtros de areia, pode-se afirmar que não houve diferença significativa entre as médias (Tabela. 2), confirmando que as frequências de aplicações adotadas não interferiram no tratamento. Também foi notado que para os efluentes dos reatores de desnitrificação, antes da adição da fonte externa de carbono, existiu uma significativa diferenciação entre as médias de DQO $(p<0,05)$. O efluente do RD1, junto com o do RD2, apresentou DQO média inferior à obtida nos outros dois casos, além de ser o único a indicar uma eficiência de remoção superior a 50\%. Essas informações sugerem que, no caso dos reatores de desnitrificação, o tempo de detenção hidráulica interferiu no processo de tratamento.

Após a adição da fonte externa de carbono para a redução biológica do nitrato, os efluentes dos reatores de desnitrificação passaram a não apresentar diferença significativa para as médias de DQO $(p<0,05)$. Mas, ao contrário do esperado, não houve um aumento expressivo nos valores encontrados, mantendo a água residuária dentro do padrão exigido pela legislação mineira (COPAM, 2008), que estipula o valor máximo de $90 \mathrm{mg} . \mathrm{O}_{2} \cdot \mathrm{L}^{-1}$ para o lançamento em corpos hídricos. A remoção da DQO pode ser atribuída à ação das bactérias desnitrificantes, que na desnitrificação oxidam a matéria orgânica e reduzem o nitrato.

Os efluentes dos filtros de areia, mesmo ao sofrerem um grande processo de remoção de matéria orgânica e de nitrificação, apresentaram altas concentrações de oxigênio dissolvido, com

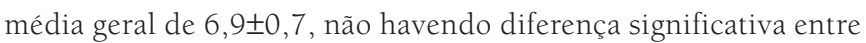
seus valores $(p<0,05)$. Segundo Tonetti et al. (2012), os valores relativamente elevados de OD demonstram a grande capacidade de aeração dos leitos operados intermitentemente, nos quais o tempo de descanso entre uma aplicação e outra ocasiona a entrada de ar para o interior dos poros da areia, sustentando o metabolismo das bactérias aeróbias e também permitindo a dissolução do oxigênio na fase líquida proveniente da disposição seguinte. A entrada de ar pode ter ocorrido tanto por meio da tubulação de aeração instalada na base do reator (Figura 2) como pela camada superficial do próprio leito de areia, visto que o sistema foi operado sem a formação do empoçamento. Ao longo da pesquisa, não ocorreu a colmatação do leito de areia.

Quanto aos efluentes dos reatores de desnitrificação, a concentração de oxigênio dissolvido anteriormente à adição de $\mathrm{Na}_{2} \mathrm{CO}_{3}$ nunca foi inferior a $4 \mathrm{mg} \cdot \mathrm{L}^{-1}$ (Figura 6). Desse modo, atendia a legislação brasileira (Brasil, 2005) referente ao enquadramento de corpos de água de classe 3. Apesar de satisfazerem essa legislação, os reatores não cumpriram sua principal função dentro do sistema de tratamento proposto, que era a de propiciar um meio adequado para a transformação do nitrato em nitrogênio gasoso, tanto no que diz respeito ao pH (Figura 5) como quanto à concentração de OD. No que tange a esse último parâmetro, segundo Dinçer e Kargi (2000), a efetividade da desnitrificação decresce quando sua concentração é superior a 0,2 mg. $\mathrm{L}^{-1}$, enquanto que, para Surampalli et al. (1997), somente quando excedia 1,0 mg. $\mathrm{L}^{-1}$ havia a inibição desse processo bioquímico.

A correção dos valores de pH com a adição de carbonato de sódio não ocasionou mudanças significativas nos valores de oxigênio dissolvido encontrados para o efluente de um mesmo reator $(p<0,05)$. No entanto, após o acréscimo da fonte externa de carbono na 58 a semana (Figura 6), observou-se uma gradativa queda da concentração de OD nos quatro reatores de desnitrificação, com uma média para o conjunto dos efluentes de 2,6士0,4 $\mathrm{mg} \cdot \mathrm{L}^{-1}$. Esse consumo pode ter sido resultante da ação das bactérias aeróbias presentes nesse reator.

No caso do reator RD1, apesar desse alto valor de OD, foi obtida uma desnitrificação que ocasionou a remoção de 43,5\% do nitrogênio total (Tabela 1). Esse resultado corrobora a afirmação de Eisentraeger et al. (2001) e Surampalli et al. (1997) de que, apesar de a desnitrificação ser sensível à presença de oxigênio dissolvido, essa reação bioquímica pode ocorrer até mesmo em concentrações próximas a 4,0 mg. $\mathrm{L}^{-1}$, sendo que tal comportamento provavelmente está associado à existência de microzonas anóxicas no floco ou no biofilme.

Cabe destacar que a concentração de sólidos suspensos totais não superou a média de $12 \mathrm{mg} \cdot \mathrm{L}^{-1}$ no efluente dos reatores de desnitricação. Após a adição da fonte externa de carbono, esses valores foram ainda menores, não ultrapassando $4 \mathrm{mg}$. $\mathrm{L}^{-1}$. 


\section{Conclusões}

Os filtros de areia proporcionaram uma grande capacidade de aeração do efluente, permitindo que, para as taxas de aplicações estudadas, houvesse uma remoção de matéria orgânica em termos de DQO que não foi significativamente diferente em qualquer dos reatores avaliados $(p<0,05)$. Tanto o efluente gerado pelos filtros de areia como pelos reatores de desnitrificação estavam abaixo do limite estipulado para a DQO (COPAM, 2008) para o lançamento em corpos hídricos. Os filtros de areia tiveram uma grande capacidade de nitrificação do afluente desde o início da operação, sendo que esse processo foi incrementado com a correção do pH do meio. Somente após a adição da fonte externa de carbono, o reator de desnitrificação que recebia uma única disposição diária de 50 L.m-2 propiciou uma diminuição na concentração de N-total. No caso, foi atingida uma remoção de 43,5\%, que atribuiu ao efluente um grau leve ou moderado para o emprego em alguma prática agrícola.

\section{Referências}

AMERICAN PUBLIC HEALTH ASSOCIATION (APHA), AMERICAN WATER WORKS ASSOCIATION (AWWA), WATER ENVIRONMENT FEDERATION (WEF). (2005) Standard Methods for the Examination of Water and Wastewater. $21^{\text {st }}$ ed. Washington DC, USA: American Public Health Association, 2005.

ASSOCIAÇÃO BRASILEIRA DE NORMAS TÉCNICAS. (1995) NBR 6502: rochas e solos: análise granulométrica conjunta. São Paulo, 1995.

BRASIL. CONSELHO NACIONAL DE MEIO AMBIENTE (CONAMA). (2005) Resolução no 357 de 17 de março de 2005. Dispõe sobre a classificação dos corpos de água e diretrizes ambientais para o seu enquadramento, bem como estabelece as condições e padrões de lançamento de efluentes, e dá outras providências. Diário Oficial da União, n. 53, de 18 de março de 2005, p. 58-63. Disponível em: <http:// www.mma.gov.br/port/conama/processos/61AA3835/LivroConama. pdf $>$. Acesso em: 28 nov. 2012.

BRASIL. CONSELHO NACIONAL DE MEIO AMBIENTE (CONAMA). (2011) Resolução no 357 de 17 de março de 2005. Dispõe sobre as condições e padrões de lançamento de efluentes, complementa e altera a Resolução no 357. Diário Oficial da União, n. 53, de 13 de maio De 2011, p. 58-63. Disponível em: <http://www.mma.gov.br/port/conama/ processos/61AA3835/LivroConama.pdf>. Acesso em: 28 nov. 2012.

CAMARGO, S.A.R.; NOUR, E.A.A. (2001) Bamboo as an anaerobic medium: effect of filter column height. Water Science and Technology, v. 44, n. 4, p. $63-70$.

ÇEÇEN, F.; GONENÇ, I. E. (1995) Criteria for nitrification and denitrification of high-strength wastes in two upflow submerged filters. Water Environmental Research. v. 67, n. 2, p. 132-142.

CONSELHO ESTADUAL DE POLÍTICA AMBIENTAL (COPAM). (2008) Deliberação Normativa $n^{\circ} 1$ de 5 de maio de 2008. Estabelece normas e padrões para qualidade das águas, lançamento de efluentes nas coleções de águas, e dá outras providências. Diário do Executivo de Minas Gerais de 13 de maio de 2008. Disponível em: <http:// http://
www.siam.mg.gov.br/sla/download.pdf?idNorma=8151>. Acesso em: 20 ago. 2013.

DINÇER, A.R.; KARGI, F. (2000) Kinetics of sequential nitrification and denitrification processes. Enzyme and Microbial Technolog, v. 27, p. 37-42.

EISENTRAEGER, A.; KLAG, P.; VANSBOTTER, B.; HEYMANN, H.; DOTT, W. (2001) Denitrification of groundwater with methane as sole hydrogen donor. Water Research, v. 35, n. 9, p. 2261-2267.

FAO - ORGANIZAÇÃO DAS NAÇÕES UNIDAS PARA AGRICULTURA E ALIMENTAÇÃO (1994). Water quality for agriculture - Irrigation and drainage paper.

FARIA, L.C.; PASQUINI, C. (1991) Flow-injection determination of inorganic forms of nitrogen by gas diffusion and conductimetry. Analytical Chemical Acta, v. 245, p. 183-190.

FORESTI, E.; ZAIAT, M.; VALLERO, M. (2006) Anaerobic processes as the core technology for sustainable domestic wastewater treatment. Review in Environmental Science and Biotechnology, v. 5, p. 3-19.

HENZE, M.; HARREMOES, P.; JANSEN, J.L.C.; ARVIN, E. (1997) Wastewater Treatment: Biological and Chemical Process. Berlim: Springer. 2 ed

HER, J.; HUANG, J. (1995) Influences of carbon source and C/N ratio on nitrate/nitrite denitrification and carbon breakthrougn. Bioresource Technology, v. 54, p. 45-51.

METCALF e EDDY. (2003) Wastewater engineering, treatment, disposal and reuse. 4 ed. Nova lorque: McGraw-Hill, International Editions.

SURAMPALLI, R.Y.; TYAGI, R.D.; SCHEIBLE, O.K.; HEIDMAN, J.A. (1997) Nitrification, denitrification and phosphorus removal in sequential bath reactor. Bioresearch Tecnhnology, v. 61, p. 151-157. 
TONETTI, A.L.; CORAUCCI FILHO, B.; NICOLAU, C.E.; BARBOSA, M.; TONON, D. (2012) Tratamento de esgoto e produção de água de reúso com o emprego de filtros de areia. Revista Engenharia Sanitária e Ambiental, v. 17, p. 287-294.

TONETTI, A.L.; CORAUCCI FILHO, B.; BERTONCINI, E.I.; OLIVEIRA, R.A.; STEFANUTTI, R. (2010) Avaliação de um sistema simplificado de tratamento de esgotos visando a utilização em áreas rurais. Revista Brasileira de Engenharia Agrícola e Ambiental, v. 14, n. 2, p. 227-234.
USEPA - UNITED STATES ENVIRONMENTAL PROTECTION AGENCY. (1993) Manual nitrogen control. Washington DC, EUA.

VAN HAANDEL, A.; MARAIS, G.O. (1999). Comportamento do sistema de lodos ativados. Campina Grande: EPGRAF.

VAN RIJN, J.; TAL, Y.; SCHREIER, H.J. (2006) Denitrification in recirculating systems: theory and applications. Aquacultural Engineering, v. 34, p. 364-376. 